\title{
Insidious reintroduction of wild poliovirus into Israel, 2013
}

E Anis ${ }^{1,2,3,4}$, E Kopel (eran.kopel@mail.huji.ac.il)1,2,4, S R Singer ${ }^{1,2,4}$, E Kaliner ${ }^{2}$, L Moerman ${ }^{1,2}$, J Moran-Gilad ${ }^{2,5}$, D Sofer6,7,

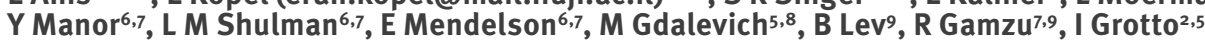

1. The Division of Epidemiology, Public Health Services, Ministry of Health, Jerusalem, Israel

2. Public Health Services, Ministry of Health, Jerusalem, Israel

3. Braun School of Public Health and Community Medicine, Hebrew University Hadassah Faculty of Medicine, Jerusalem, Israel

4. These authors contributed equally to this study

5. Faculty of Health Sciences, Ben-Gurion University of the Negev, Beer Sheva, Israel

6. Central Virology Laboratory, Public Health Services, Ministry of Health, The Chaim Sheba Medical Centre, Tel Hashomer, Israel

7. Sackler Faculty of Medicine, Tel-Aviv University, Tel Aviv, Israel

8. South District Health Office, Ministry of Health, Beer Sheva, Israel

9. Ministry of Health, Jerusalem, Israel

Citation style for this article:

Anis E, Kopel E, Singer SR, Kaliner E, Moerman L, Moran-Gilad J, Sofer D, Manor Y, Shulman LM, Mendelson E, Gdalevich M, Lev B, Gamzu R, Grotto I. Insidious reintroduction of wild poliovirus into Israel, 2013. Euro Surveill. 2013;18(38): pii=20586. Available online: http://www.eurosurveillance.org/ViewArticle. aspx?Articleld $=20586$

Article submitted on o9 September 2013 / published on 19 September 2013

Israel was certified as polio-free country in June 2002, along with the rest of the World Health Organization European Region. Some 11 years later, wild-type polio virus 1 (WPV1) was isolated initially from routine sewage samples collected between 7 and 13 April 2013 in two cities in the Southern district. WPV1-specific analysis of samples indicated WPV1 introduction into that area in early February 2013. National supplementary immunisation with oral polio vaccine has been ongoing since August 2013.

\section{Detection of wild poliovirus in Israel}

Wild poliovirus type 1 (WPV1) was isolated from routine samples collected during epidemiological week 15 (7 to 13 April 2013) in sewage treatment facilities in Beer Sheva and Rahat, two cities in Israel's Southern district. Beer Sheva, the regional commercial centre, has a population of about 200,000 . It is situated $20 \mathrm{~km}$ south of Rahat and there is considerable population movement and commerce between the two cities.

\section{Background}

Poliomyelitis (polio) has been a notifiable disease in Israel since 1951. WPV 1 predominated during the large, pre-vaccine national epidemics during 1949 to $1956[1,2]$ with a peak incidence of 129.4 cases per 100,000 of the general (mostly Jewish) population in 1950 [1]. Substantial control of polio was achieved by the mid-1960s (0.1 per 100,000 in 1965) through universal childhood vaccination with trivalent oral polio vaccine (OPV), followed by low-level activity throughout the 1970 s (0.2-0.9 per 100,000), particularly in the Jewish population (0.1 per 100,000 Jewish population). Annual campaigns with type 1 monovalent OPV further reduced polio incidence also among the non-Jewish population in the 1980 s ( 0.1 to 0.3 per 100,000 nonJewish population) [1].
Israel has not had a polio case since an outbreak in 1988 , in which 15 poliovirus-infected people had paralytic polio, mostly in the Hadera sub-district in the northern part of the country $[1,3]$, following importation of WPV 1 from northern Egypt the year before the outbreak [1,4]. Most of the 1988 outbreak cases had received OPV in the past. A mass trivalent OPV vaccination campaign ended the outbreak [3].

In 1990, a routine national vaccine programme - combining three inactivated polio vaccine (IPV) doses with three trivalent OPV doses - was implemented. This schedule continued until 2005, when OPV was discontinued three years after the polio-free status certification by the World Health Organization (WHO), in June

\section{TABLE 1*}

Historical and current routine childhood vaccine schedules against poliomyelitis, Israel, 1957-2013

\begin{tabular}{|l|c|c|c|c|}
\hline Age & $1957-1960$ & $1961-1989^{\mathrm{a}}$ & $1990-2004$ & $2005-$ present \\
\hline 2 months & - & OPV & IPV & IPV \\
\hline 4 months & IPV & OPV & OPV + IPV & IPV \\
\hline 6 months & IPV & OPV & OPV & IPV \\
\hline 12 months & IPV & OPV & OPV + IPV & IPV \\
\hline 6 years & - & - & OPV & - \\
\hline 7 years & - & - & - & IPV \\
\hline 13 years & - & - & OPV & - \\
\hline
\end{tabular}

IPV: inactivated polio vaccine; OPV: oral polio vaccine (trivalent).

Between 1982 and 1988, two of the 15 sub-districts in the country used IPV at the age of 2, 3.5 and 10 months. 
2002 [1]. The IPV-only schedule since 2005 prescribes three IPV doses by the age of six months with two additional booster doses at 12 months and at seven years (second elementary grade) (Table 1). The 2012 national IPV3 coverage was 95\% [5].

Israel has maintained a routine environmental polio surveillance programme since 1988 , through monthly sampling of eight to 10 sewage treatment facilities in largely populated areas or areas considered sentinels of risk for importation of WPV, such as Rahat, a major Bedouin city, which was the initial importation locus of the 1988 WPV1 outbreak [4]. Additionally, since 1996, notification of cases with acute flaccid paralysis (AFP) up to the age of 15 years has been mandated by law and active AFP surveillance has been implemented. Since then, the level of reporting fluctuated, sometimes below the WHO threshold (1 case of AFP per 100,000 population «15 years of age). As a consequence, the structure of the active AFP surveillance system was reorganised several times in the past years, and since January 2013, the national Division of Epidemiology contact directly, on a weekly basis, each representative of the relevant clinical care units in the country, in order to obtain the complete information on any suspected AFP cases, and assuring the required clinical sampling for the necessary laboratory tests.

Here we describe the epidemiology of the reintroduction of WPV 1 into Israel in 2013 , a potential public health emergency at the national level and public health threat at the global level.

\section{Epidemiological investigation}

\section{Environmental surveillance}

As part of the regular environmental surveillance, sewage samples are processed at the Central Virology Laboratory in Tel Hashomer. Poliovirus is isolated from the samples by infecting recombinant mouse cell line L2OB according to WHO guidelines $[6,7]$. Individual plaques propagated in tube cultures are then analysed by real-time polymerase chain reaction (PCR) using United States (US) Centers for Disease Control and Prevention (CDC) analytical kits designed for identification of polioviruses and differentiation between vaccine and wild types [8], followed by characterisation by genome sequencing [9].

The samples collected in the sewage treatment facilities of Rahat and Beer Sheva are part of this routine environmental surveillance. At the end of May 2013, the Central Virology Laboratory confirmed that WPV 1 had been detected in two sewage samples taken in the Rahat and Beer Sheva facilities in epidemiological week 15 (7-13 April 2013).

A WPV1-specific analysis of samples from early 2013 indicated WPV1 introduction into Beer Sheva in February 2013 (week 6, 3-9 February) and into Rahat in March 2013 (week 11, 10-16 March). The isolates from
Rahat and Beer Sheva were identified as non-Sabin poliovirus type 1 belonging to the SOAS (South Asia) lineage of WPV1, which has been circulating in Pakistan in recent years, and which was also isolated from sewage samples in the Cairo region, Egypt, in December 2012 [10].

Intensified environmental surveillance

Subsequently, environmental surveillance was extended and intensified to cover more sewage sampling sites nationally. As of 1 September 2013, WPV 1 has been detected in 87 of 220 samples tested that were obtained from 79 sewage sampling sites in Israel and collected after 3 February 2013 (Figure). In the southern district, most of the treatment facilities with samples that have been continuously WPV 1 positive to date have been in areas inhabited by Bedouin communities. WPV1 was also detected in several sewage sampling sites in central Israel, mostly around Arab or mixed Jewish-Arab communities, indicating countrywide transmission.

\section{Public health response from end May to 5 August 2013}

The following instant actions were carried out, following the detection of WPV 1 in Israel.

- In Rahat and the surrounding area, where substantial and continuous WPV 1 circulation has been detected in samples collected since the first quarter of 2013, an IPV catch-up vaccination campaign was initiated in order to maximise the routine childhood IPV coverage and to administer a booster IPV to all adults who had no evidence of prior booster vaccination in adulthood (i.e. before travel to polio endemic countries), with special outreach to sewage facility workers and migrant communities whose members had migrated through Egypt since 2007 [11].

- A national hygiene campaign was initiated to raise public awareness of wild poliovirus circulation and hand-washing and personal hygiene and in preparation for a widespread OPV supplementary immunisation activity.

- In order maximise OPV coverage, professional information concerning poliovirus and vaccination was made available to physicians throughout the country as well as to the public, using diverse communication channels - traditional media, social media, and the Internet [12].

Enhanced surveillance of acute flaccid paralysis After the isolation of WPV1 in sewage, surveillance for AFP was expanded in June 2013, to include all age groups.

From 1 January 2013 to 1 September 2013, 45 cases of AFP had been actively detected, of which, 17 were children 15 years of age. Three of these children were 
Locations of sewage samples positive for wild poliovirus type 1 identified through environmental surveillance, Israel, by district, 3 February-12 September 2013
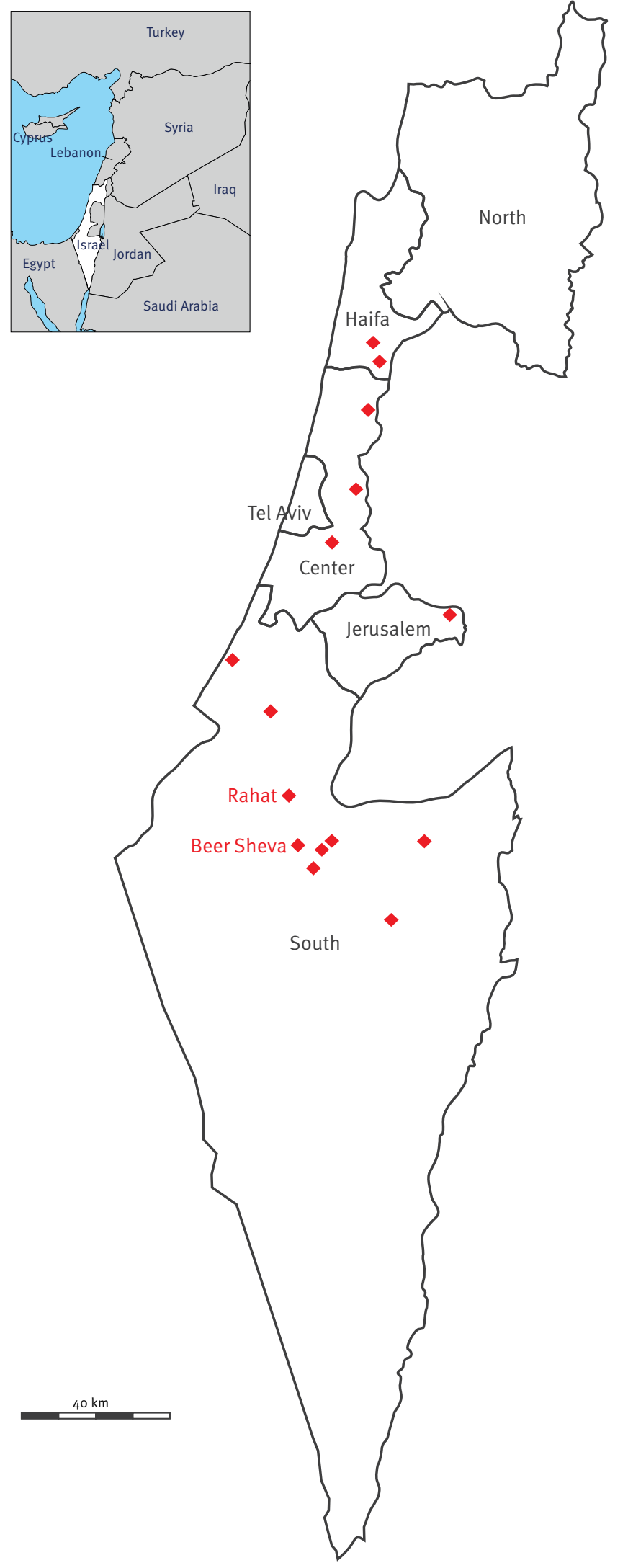

defined as 'hot' cases (i.e. lacking a complete series of routine childhood IPV immunisation due to young age or parental objection) [13]. The estimated annual AFP incidence in 2013, based on cases detected so far, is 1.15 cases per 100,000 population $<15$ years of age. All 45 AFP cases tested negative for WPV1.

No case of paralytic polio has been detected to date in Israel.

\section{Start of aseptic meningitis surveillance}

National aseptic meningitis surveillance was also initiated in June 2013. As of 28 August 2013, a total of 156 cases of aseptic meningitis were reported nationally: none was positive for poliovirus; 65 cases $(42 \%)$ were positive for other non-polio enteroviruses.

\section{Ongoing national supplementary \\ immunisation activity}

A supplementary immunisation activity using bivalent OPV $[14,15]$ was initiated in the Southern district on 5 August 2013 and has been expanded nationally since 18 August, with the objective of rapidly interrupting WPV 1 transmission across the country, particularly in children previously vaccinated according to the IPVonly programme, by inducing effective intestinal immunity $[16,17]$.

All children born after 1 January 2004, who have received at least one dose of IPV in the past, were considered vaccine candidates. This approach is in accordance with that used in the routine national immunisation schedule during 1990 to 2004, which has a formidable international safety profile [18]. Vaccine candidates who have immunodeficiency conditions or those living with immunocompromised household contacts are not vaccinated with bivalent OPV.

As of 15 September 2013, approximately 750,000 of about 1,200,000 eligible bivalent OPV candidates (63\%, inter-district range: $45-83 \%$ ) were vaccinated nationwide (Table 2).

The Israeli response to the finding of WPV 1 has been fully coordinated with leading local epidemiology, infection disease and paediatric experts, as well as WHO and the US CDC. A joint WHO/CDC mission visited Israel in June 2013 and its experts have been consulted at every stage of the outbreak response.

\section{Discussion}

The last widespread circulation of wild poliovirus in Israel was 25 years ago, resulting in a national outbreak with cases of permanent paralytic polio [3]. The major difference between the 1988 outbreak in Israel and other outbreaks of wild poliovirus infection in recent years in other developed countries $[19,20]$ that used an IPV-only routine vaccination schedule, is the early detection of silent virus circulation through an existing early warning system, involving national environmental 


\section{TABLE 2}

Bivalent oral polio vaccine coverage $\mathrm{a}^{\mathrm{a}, \mathrm{b}}$, by district, since the start of the supplementary immunisation activity on 5 August 2013, Israel

\begin{tabular}{|l|c|}
\hline District & Vaccine coverage (\%) \\
\hline Northern & 83 \\
\hline Southern & c \\
\hline Haifa & 69 \\
\hline Ashkelon & 63 \\
\hline Central & 54 \\
\hline Tel Aviv & 49 \\
\hline Jerusalem & 45 \\
\hline Total & 63 \\
\hline
\end{tabular}

Among about 1,200,000 eligible vaccine candidates, born after 1 January 2004 .

b Data as of 15 September.

In the Bedouin population of the Southern district communities, the bivalent oral polio vaccine coverage surpassed $80 \%$.

surveillance. This early detection allowed for further investigation and planning of a national response well in time.

An apparent single event of long-distance WPV1 importation from Pakistan, where the SOAS genotype has circulated in 2012, to Egypt, possibly by an asymptomatic carrier or carriers, and the further importation to Israel - a journey of thousands of kilometres - has resulted in nearly nationwide WPV1 spread. This widespread WPV1 circulation might have been facilitated by the substantial non-OPV immunised cohort of children, who were born after the withdrawal of routine OPV doses from the national immunisation programme in 2005.

Notably, the highly probable chain of events that lead to the re-introduction of WPV 1 into Israel in 2013 is not the first of its kind. Other possible long-distance point importations into decades-long polio-free countries were identified, in Finland and the Netherlands, following the paralytic polio outbreaks of 1986 and 1992, respectively [19-22]. This is in contrast to the endemic, Middle-Eastern origin of the 1988 outbreak due to WPV 1 in Israel $[1,3,4]$.

The detection of WPV 1 in 2013 in Israel should therefore alert polio-free countries and global health organisations, which could confront a similar situation, given the increased mobility of people and populations, as long as wild poliovirus continues to be endemic in several parts of the world. Furthermore, our findings are also relevant to the global debate related to polio preventive measures such as routine national environmental surveillance and reinstitution of combined IPV and
OPV routine immunisation schedule, even in polio-free countries with high IPV coverage [23].

\section{Acknowledgements}

We thank the following individuals for their contributions (by surname alphabetical order): Elran Bella, Prof. Engelhard Dan, Honovich Mira, Prof. Leventhal Alex, Dr. Levine Hagai, Prof. Linder Nehama, Prof. Rahav Galia, Dr. Rubin Lisa, Prof. Rishpon Shmuel, Prof. Shalit Itamar, Prof. Shohat Tami, Dr. Slater Paul, Prof. Somekh Eli, Dr. Tasher Diana. We also thank the joint WHO/CDC mission.

\section{Conflict of interest}

None declared.

\section{Authors' contributions}

Emilia Anis, Eran Kopel, Shepherd R. Singer and Itamar Grotto wrote the first draft of the manuscript. All authors revised and approved the final version of the manuscript.

* Authors' correction

In the last row of Table 1, '16 years' was corrected to '13 years'. This correction was made on 18 November 2013 at the request of the authors.

\section{References}

1. Swartz TA. The epidemiology of polio in Israel. An historical perspective. Israel Center for Disease Control (ICDC), Ministry of Health; Tel Aviv: Nov 2008. Publication 317. Available from: http://www.old.health.gov.il/Download/pages/Polio_ inlsrae251109l.pdf

2. Yekutiel P, Levinger EL, Muhsam HV, Yekutiel MP. Poliomyelitis outbreak in Israel, 1950-1. Bull World Health Organ. 1955;12(4):651-76. PMid:14379003. PMCid:PMC 2542293.

3. Slater PE, Orenstein WA, Morag A, Avni A, Handsher R, Green MS, et al. Poliomyelitis outbreak in Israel in 1988: a report with two commentaries. Lancet. 1990;335(8699):1192-5; discussion 1196-8. http://dx.doi.org/10.1016/0140-6736(90)92705-M

4. Shulman LM, Handsher R, Yang CF, Yang SJ, Manor J, Vonsover A, et al. Resolution of the pathways of poliovirus type 1 transmission during an outbreak. J Clin Microbiol. 2000;38(3):945-52. PMid:10698978. PMCid:PMC86309.

5. World Health Organization (WHO). WHO vaccine-preventable diseases: monitoring system. 2013 global summary. Geneva: WHO. [Accessed 1 Sep 2013]. Available from: http://apps.who. int/immunization monitoring/globalsummary/countries?count rycriteria\%5Bcountry\%5D\%5B\%5D=ISR

6. World Health Organization (WHO). Polio laboratory manual. 4th ed. Geneva: WHO; 2004. WHO/IVB/04.10. Available from: http://www.who.int/vaccines/en/poliolab/WHO-PolioManual-9.pdf

7. Manor Y, Blomqvist S, Sofer D, Alfandari J, Halmut T, Abramovitz B, et al. Advanced environmental surveillance and molecular analyses indicate separate importations rather than endemic circulation of wild type 1 poliovirus in Gaza district in 2002. Appl Environ Microbiol. 2007;73(18):5954-8. http://dx.doi.org/10.1128/AEM.02537-06. PMid:17660306. PMCid:PMC 2074904.

8. Kilpatrick DR, Yang CF, Ching K, Vincent A, Iber J, Campagnoli $R$, et al. Rapid group-, serotype-, and vaccine strainspecific identification of poliovirus isolates by real-time reverse transcription-PCR using degenerate primers and probes containing deoxyinosine residues. J Clin Microbiol. 2009;47(6):1939-41. http://dx.doi.org/10.1128/JCM.00702-09. PMid:19386844. PMCid:PMC2691077. 
9. Kilpatrick DR, Iber JC, Chen Q, Ching K, Yang SJ, De L, et al. Poliovirus serotype-specific VP1 sequencing primers. J Virol Methods. 2011;174(1-2):128-30. http://dx.doi.org/10.1016/j. jviromet.2011.03.020. PMid:21440569.

10. ProMED-mail. Poliomyelitis - worldwide (01): Egypt ex Pakistan, Niger. Archive Number 20130122.1509210. 22 Jan 2013. Available from: http://www.promedmail.org/direct. php?id=20130122.1509210

11. The Knesset Research and Information Center. [The management of infiltrators from the Egyptian border]. 26 May 2010. [Hebrew]. Available from: http://www.knesset.gov.il/ $\mathrm{mmm} / \mathrm{data} / \mathrm{pdf} / \mathrm{m02524.pdf}$

12. Ministry of Health $(\mathrm{MoH})$. Supplemental polio vaccination campaign. "Two Drops" - the national supplementary immunisation activity official website. Jerusalem: $\mathrm{MoH}$. [Accessed 1 Sep 2013]. Available from: http://www.health.gov. il/English/Topics/Vaccination/two_drops/Pages/default.aspx

13. World Health Organization (WHO). Guidelines on responding to the detection of wild poliovirus in the WHO European Region. Copenhagen: WHO; 2007. Available from: http://www.euro. who.int/_data/assets/pdf_file/ooo8/86498/E91123.pdf

14. World Health Organization (WHO). WHO package insert. Polio Sabin ${ }^{T M}$ One and Three (oral). WHO model insert (June 09). GlaxoSmithKline Biologicals. Bivalent Oral Poliomyelitis Vaccine Types 1 and 3 (bOPV). Geneva: WHO. [Accessed 1 Sep 2013]. Available from: http://www.who.int/immunization standards/vaccine_quality/OPV_bivalent_GSK_WHO_ package insert text english.pdf

15. Sutter RW, John TJ, Jain H, Agarkhedkar S, Ramanan PV, Verma $\mathrm{H}$, et al. Immunogenicity of bivalent types 1 and 3 oral poliovirus vaccine: a randomised, double-blind, controlled trial. Lancet. 2010;376(9753):1682-8. http://dx.doi. org/10.1016/S0140-6736(10)61230-5

16. Hird TR, Grassly NC. Systematic review of mucosal immunity induced by oral and inactivated poliovirus vaccines against virus shedding following oral poliovirus challenge. PLoS Pathog. 2012;8(4):e1002599. http://dx.doi.org/10.1371/journal. ppat.1002599. PMid:22532797. PMCid:PMC3330118.

17. Swartz TA, Green MS, Handscher R, Sofer D, Cohen-Dar M, Shohat T, et al. Intestinal immunity following a combined enhanced inactivated polio vaccine/oral polio vaccine programme in Israel. Vaccine. 2008;26(8):1083-90. http:// dx.doi.org/10.1016/j.vaccine.2007.12.021. PMid:18241962.

18. World Health Organization (WHO). Scientific evidence in support of: Note for the record: 5 th meeting of the SAGE Working Group, World Health Organization, Geneva, September 3-4, 2012. Geneva: WHO; 2012. Available from: http://www. who.int/immunization/sage/meetings/2012/november/3_ SAGE_WG_Scientific_Evidence220ct2012.pdf

19. Oostvogel PM, van Wijngaarden JK, van der Avoort HG, Mulders MN, Conyn-van Spaendonck MA, Rümke HC, et al. Poliomyelitis outbreak in an unvaccinated community in the Netherlands, 1992-93. Lancet. 1994;344(8923):665-70. http://dx.doi. org/10.1016/S0140-6736(94)92091-5

20. Hovi T, Cantell K, Huovilainen A, Kinnunen E, Kuronen T, Lapinleimu K, et al. Outbreak of paralytic poliomyelitis in Finland: widespread circulation of antigenically altered poliovirus type 3 in a vaccinated population. Lancet. 1986;1(8495):1427-32. http://dx.doi.org/10.1016/ S0140-6736(86)91566-7

21. Pöyry T, Kinnunen L, Kapsenberg J, Kew O, Hovi T. Type 3 poliovirus/Finland/1984 is genetically related to common Mediterranean strains. J Gen Virol. 1990;71(Pt 11):2535-41. http://dx.doi.org/10.1099/0022-1317-71-11-2535. PMid:1701473.

22. Simonen ML, Roivainen M, Iber J, Burns C, Hovi T. Outbreak of poliomyelitis in Finland in 1984-85 - Re-analysis of viral sequences using the current standard approach. Virus Res. 2010;147(1):91-7. http://dx.doi.org/10.1016/j. virusres.2009.10.012. PMid:19883702.

23. Tulchinsky TH. Polio eradication: end-stage challenges. Bull World Health Organ. 2005;83(2):160. PMid:15744411. PMCid:PMC2623815. 